\title{
UNA NUEVA ESPECIE DE MALAXIS (ORCHIDACEAE) DE FLORES GRANDES DEL NORTE DE CHIAPAS
}

\author{
Gerardo A. Salazar Chavez y Miguel A. Soto Arenas \\ Herbario de la Asociación Mexicana de Orquideología, A.C. (AMO) \\ Apdo. Postal 53-123 \\ 11320 México, D.F., México.
}

\begin{abstract}
RESUMEN
Se describe la nueva especie Malaxis greenwoodiana Salazar y Soto Arenas, notable por presentar flores desusadamente grandes para el género. Es similar a M. lepanthiflora (Schltr.) Ames, del sur de Chiapas, Guatemala y El Salvador, pero se distingue de ella por la forma de los lóbulos basales del labelo y de los pétalos. Hasta ahora sólo ha sido colectada en una zona del norte de Chiapas conocida como la Selva Negra.
\end{abstract}

\begin{abstract}
A new species, Malaxis greenwoodiana Salazar and Soto Arenas, with flowers unusually large for the genus, is described. It is similar to M. lepanthiflora (Schltr.) Ames, from southern Chiapas, Guatemala and El Salvador, from which it is easily distinguished on the basis of different shape of basal lip lobes and of petals. It is known only from an area in the north of Chiapas known as the Selva Negra.
\end{abstract}

Durante una excursión al estado de Chiapas, realizada por los autores hace algún tiempo, fueron colectadas varias plantas de Malaxis con flores de tamaño desusadamente grande para este género, cuyas especies por regla general tienen flores de pocos milímetros de diámetro.

El estudio del material mostró que se trataba de una entidad relacionada con un grupo de especies cuyo representante más conocido es Malaxis excavata (Lindl.) O. Ktze. Las especies mexicanas y centroamericanas de este grupo presentan plantas epífitas o epígeas, frecuentemente con rizomas alargados, hojas grandes y membranáceas y flores de tamaño relativamente grande; el labelo carnoso, con 2 profundas depresiones alargadas en el disco y aurículas o lóbulos basales más o menos triangulares, agudos, retrorsos, por lo cual la base del labelo es descrita a veces como semilunada, y generalmente un lóbulo apical terminado en 3 dientes. La cavidad estigmática forma una depresión terminal en el ápice de la columna, no en la superficie ventral como en otros grupos de especies dentro del mismo género. Cada uno de los dos polinarios está constituido por dos polinios muy desiguales y presenta un viscidio formado por una gota viscosa.

La revisión del material de herbario y de la bibliografía pertinente condujeron a la conclusión de que la entidad en cuestión es una especie distinta, no descrita. La especie más similar es M. lepanthiflora (Schltr.) Ames, recientemente descubierta en el sur de Chiapas (M.A. Soto Arenas 5819 y E. Martínez, AMO!) y previamente conocida de Guatemala y EI Salvador, la cual presenta dimensiones florales y aspecto general similares (véase: Ames \& 
Correll, 1952; Hamer, 1974; Mansfeld, 1931; Schlechter, 1918), aunque algunas diferencias en la formay tamaño de los lóbulos basales del labelo y la forma de los pétalos permiten separarlas con facilidad. Siguiendo la clave de Williams (1951) se hace evidente que este taxon no corresponde a ninguna de las especies mexicanas, principalmente en virtud de la presencia de grandes lóbulos basales redondeados o subcuadrados y no de aurículas agudas, retrorsas, propias de $M$. excavatay de $M$. maxonii Ames, las 2 únicas especies de este grupo reconocidas previamente para México (Soto Arenas, 1989; Williams, op. cit.).

De acuerdo con la información expuesta, se propone la siguiente especie nueva:

\section{Malaxis greenwoodiana Salazar et Soto Arenas, sp. nov. (Fig. 1)}

M. lepanthiflorae (Schltr.) Ames similis, a qua labello conspicue trilobato, lobis basalibus subquadratis vel suborbicularibus lobum apicalem trapezoideum subaequantibus, petalis triangulari-ovatis vel triangulari-lanceolatis attenuatis vel caudatis differt.

Hierba terrestre, glabra, con excepción de las raíces, de $16-21 \mathrm{~cm}$ de alto. Raíces delgadas, lanuginosas, blanquecinas, originadas en la base de los seudobulbos, de 0.5-1 mm de diámetro. Rizoma conspicuo, delgado, situado entre 2 seudobulbos contiguos, blanquecino, de 1-3 cm de largo y 1.5-5 mm de diámetro, envuelto completamente por 2-3 vainas escariosas, tubulares, amplias, imbricadas, obtusas, de $0.9-3 \mathrm{~cm}$ de largo, las cuales se van perdiendo con el tiempo. Seudobulbos cónico-ovoides, heteroblásticos, de color verde translúcido, de 21-30 $\mathrm{mm}$ de largo y 5-11 mm de diámetro (en seco), cuando jóvenes completamente cubiertos por una vaina tubular, membranácea, obtusa, de $2.5-3.5 \mathrm{~cm}$ de largo, que se deshace en fibras a medida que el seudobulbo madura. Hojas 2, pecioladas, cabalmente desarrolladas cuando el seudobulbo aún no completa su desarrollo, aparentemente deciduas; pecíolos tubulares, en la porción basal, arriba acanalados, algo inflados, de $3-5 \mathrm{~cm}$ de largo desde el ápice del seudobulbo hasta la base de la lámina foliar, de $2-4 \mathrm{~mm}$ de diámetro; láminas foliares subopuestas, ascendentes, ovado-elípticas, base ampliamente cuneada a redondeada, conduplicada, márgenes ondulado-crenulados a enteros, ápice abruptamente acuminado, textura membranácea, color verde claro translúcido, de 4.5-7.5 cm de largo y 1.8-4.3 cm de ancho. Inflorescencia racemosa, erecta, originada del ápice del seudobulbo en desarrollo, envuelta en su parte inferior por los pecíolos y emergiendo entre las bases de las láminas foliares, hasta de $15 \mathrm{~cm}$ de largo, medidos desde las bases de las láminas foliares hasta el ápice del racimo; pedúnculo delgado, sin brácteas, al parecer ligeramente alado, blanco-amarillento, de 9-11 cm de largo entre la base de las láminas foliares y la primera bráctea floral, de 1-2 mm de diámetro; racimo corto, en ocasiones subcorimboso, hasta de $4 \mathrm{~cm}$ de largo y $4 \mathrm{~cm}$ de diámetro, con 10-25 flores que van abriendo sucesivamente, pudiendo estar 3 ó 4 flores abiertas a la vez. Brácteas florales extendidas casi en ángulo recto con el raquis, membranáceas, de color amarillo translúcido, triangular-lanceoladas a triangular-ovadas, acuminadas, de 3-6 mm de largo. Flores entre las mayores del género, poco vistosas, no resupinadas, de 1.5-2 cm de largo entre los ápices del sépalo dorsal y los laterales; sépalos y pétalos de color verde matizado de café-rojizo, labelo verde oscuro. Ovario extendido en un ángulo de $45^{\circ}-70^{\circ}$ respecto del raquis, filiforme, ligeramente engrosado cerca del ápice, recto, de 9-14 mm de largo y menos de $1 \mathrm{~mm}$ de diámetro en la mitad basal. Sépalos extendidos, con 
pocos idioblastos dispersos conteniendo cristales, el dorsal libre, ampliamente ovado a ovadoelíptico, agudo a cortamente acuminado, muy convexo, 5-nervado, de 8.5-10 mm de largo y 6$7.5 \mathrm{~mm}$ de ancho; los laterales libres o unidos entre sí en la base por hasta $1 \mathrm{~mm}$, ligeramente oblicuos, lanceolados a lanceolado-elípticos, agudos a subagudos, convexos, 3-nervados, en ocasiones con el nervio exterior bifurcado y entonces pareciendo 4-nervados, de $9 \mathrm{~mm}$ de largo y 3-3.5 $\mathrm{mm}$ de ancho. Pétalos triangular-ovados a triangular-lanceolados, atenuados a caudados, fuertemente recurvados, uninervados, con pocos idioblastos dispersos similares a los de los sépalos, de 5.5-6 mm de largo y 1.5-2.5 mm de ancho. Labelo sésil, carnoso, conspicuamente trilobado, algo más ancho que largo, cordiforme-hastado en contorno general, con idioblastos dispersos conteniendo cristales, de $3.3-4.5 \mathrm{~mm}$ de largo total y $5-5.5 \mathrm{~mm}$ de ancho entre los lóbulos laterales al extender; disco muy carnoso, con 2 depresiones longitudinales, profundas, de bordes ligeramente elevados, separadas entre sí por un tabique grueso, surcado en la base, originadas cerca de la base del labelo y terminando en la base del lóbulo medio; lóbulos basales subcuadrados, suborbiculares u oblicuamente obovados, redondeados, ligeramente retrorsos, en posición natural incurvos a los lados de la columna, de tamaño subigual al lóbulo apical, de 1.5-1.75 mm de largo y 2-2.25 mm de ancho; lóbulo apical trapezoide, tridentado en el ápice, plano, de 2-2.5 mm de largo y 2.5-3 mm de ancho en la base, los dientes laterales cortos, redondeados, el diente central agudo, prominente, de 0.75-1 mm de largo. Columna muy corta, gruesa, truncada, subcuadrada, con muchos idioblastos con cristales, de $1.5 \mathrm{~mm}$ de largo y ancho, con un diente corto a cada lado de la antera. Antera transversalmente oblonga, erecta, bilocular, de ca. $0.75 \mathrm{~mm}$ de largo y $1.25 \mathrm{~mm}$ de ancho. Polinarios 2, cada uno compuesto por 2 polinios de tamaño muy desigual, el mayor subovoide, el menor lingüiforme, unidos en el ápice a un viscidio consistente en una gota viscosa; los viscidios están ampliamente separados entre sí a los lados del ápice del rostelo. Rostelo obscuramente bilobado, prominente en el ápice de la columna. Cavidad estigmática terminal, ligeramente cóncava, limitada arriba por el rostelo y abajo por una extensión del tejido del vientre de la columna (no forma una superficie plana ventral). Cápsula no vista.

HOLOTIPO: MEXICO. CHIAPAS: municipio de Rayón. Km 105 de la carr. Tuxtla Gutiérrez-Villahermosa, aprox. 7 km arriba de Rayón. 1720 m s.n.m. Selva mediana perennifolia de lauráceas con Persea, Cedrela, Oecopetalum, Dalbergia. Terrestre, sitio abierto, en talud muy húmedo a la orilla de la carretera, junto a Stanhopea graveolens. Labelo verde oscuro, pétalos café-verdoso-rojizo. 11 de septiembre de 1985. M. A. Soto Arenas 1563, G. A. Salazar \& L. M. Calvo, (AMO). ISOTIPOS: AMES, K, MEXU.

M. greenwoodiana es conocida únicamente de la colección tipo, procedente de las cercanías de Rayón, en el norte de Chiapas, en la zona conocida como la Selva Negra. Fue encontrada creciendo en un talud muy húmedo con helechos, begonias, Pilea y otras plantas herbáceas, en un lugar abierto a la orilla de la carretera, al borde de la selva mediana 


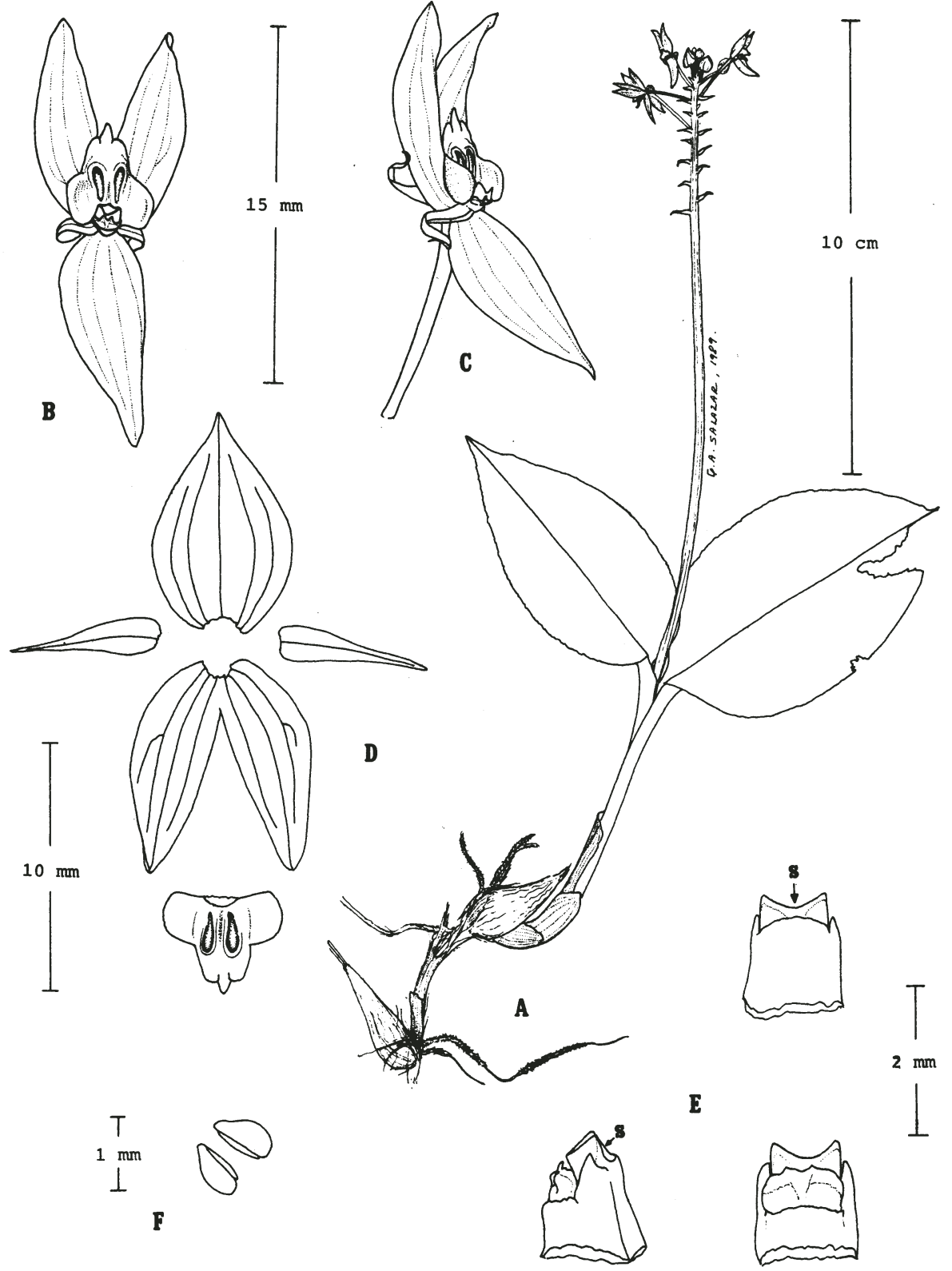

Fig. 1. Malaxis greenwoodiana. A. Aspecto de la planta; B. Flor; C. Flor, vista 3/4 lateral; D. Disección floral; E. Columna, vistas lateral, ventral y dorsal; F. Polinarios; s. estigma. (Dibujo de G. A. Salazar Chávez, preparado del holotipo). 
perennifolia de lauráceas, a 1720 m s.n.m. Se colectó en floración en septiembre.

No se sabe cuál es el estado actual de conservación de esa población, ni se ha encontrado material en los herbarios que indique que esta especie se encuentre en otros lugares de México. La zona estaba siendo afectada por la tala y la quema del bosque para abrir potreros y parcelas de cultivo. El hecho de que las plantas crecían en un talud a la orilla de la carretera podría sugerir que la especie tolera cierto grado de disturbio ambiental. En la misma localidad, pero en el interior del bosque, crecía la única población conocida en México de Malaxis pandurata (Schltr.) Ames y otras especies de orquídeas raras o amenazadas.

Este taxon se distingue de otros del género Malaxis por sus flores muy grandes, de1.5$2 \mathrm{~cm}$ de largo. Malaxis lepanthiflora, la especie más similar, es muy parecida vegetativamente y tiene flores de forma y dimensiones similares, pero el labelo con lóbulos basales triangularfalcados, agudos, retrorsos y los pétalos angostamente linear-lanceolados, agudos, la distinguen de $M$. greenwoodiana, que tiene los lóbulos basales del labelo subcuadrados a suborbiculares, redondeados, y los pétalos triangular-ovados a triangular-lanceolados, atenuados a caudados.

Esta especie es nombrada en honor de Ed Greenwood, quien durante muchos años se ha dedicado al estudio de las orquídeas mexicanas, reuniendo un acervo de información que sirve de base para gran parte del trabajo que se realiza actualmente en el Herbario de la Asociación Mexicana de Orquídeología.

\section{AGRADECIMIENTOS}

Se agradece al Dr. Fernando Chiang la traducción al latín de la diagnosis y sus comentarios al manuscrito, y a la Biól. Luz María Calvo su entusiasta colaboración en la colecta de esta especie.

\section{LITERATURA CITADA}

Ames, O. y D.S. Correll, 1952. Orchids of Guatemala. Fieldiana: Botany 26(1): 262-278.

Hamer, F., 1974. Las Orquideas de El Salvador. Vol. 2. Ministerio de Educación. San Salvador. pp. 9495.

Mansfeld, R., 1931. Blütenanalysen neuer Orchideen von R. Schlechter. II. Mittelamerikanische Orchideen. Fedde Repert. Sp. Nov. Reg. Veg. 59: t. 15, Nr. 57.

Schlechter, R., 1918. Orchidaceae novae et criticae. Fedde Repert. Sp. Nov. Reg. Veg. 15: $193-217$.

Soto Arenas, M. A., (1988) 1989. Listado actualizado de las orquideas de México. Orquídea (Méx.) 11: 231-276.

Williams, L. O., 1951. The Orchidaceae of Mexico. Ceiba 2 (1-4): 107-120. 